\title{
Impact of combined precut techniques on selective biliary cannulation
}

\author{
Emilio J. de-la-Morena-Madrigal
}

\author{
Digestive Diseases Departments. Hospital La Zarzuela. Hospital Moncloa. \\ Hospital Beata María Ana de Jesús. Madrid, Spain
}

\begin{abstract}
Introduction: simple biliary cannulation techniques obtain a success rate of $80-95 \%$. Advanced precut techniques are not immediately successful in 10-40\% of cases. Between extreme options such as a second attempt a few days later or an immediate attempt by the transparietal route, an alternative precut technique may be used as a rescue strategy for the initially failed procedure. The purpose of this study was to assess the efficacy and safety of the combined use of two precut techniques when immediate biliary access is not granted by an initial procedure.

Patients and method: a retrospective analysis of a personal series of precut (needle-knife and transpancreatic) sphincterotomies, both alone and in combination.

Results: five hundred sixty nine $\mathrm{ERCPs}$ (endocopic retrograde cholangio-pancreatography) met the inclusion criteria for the analysis. Simple cannulation was obtained in 444 (78\%) of them. In all, 119 (21\%) precuts were attempted and 110 (92.4\%) were successful, which raised the overall cannulation rate to $97.4 \%$. Ninety-five (80\%) precuts were successful with the initial technique. Rescue with the alternative technique was attempted for 20 failures with a successful outcome in 15, which raised the overall success rate to $92 \%$. The combination of needle-knife precut plus transpancreatic precut raised the success rate from $87 \%$ to $94 \%$. The combination of transpancreatic precut plus needle-knife precut raised the success rate from 70\% to 90\%. Among all 96 patients with available follow-up data, 17 (18\%) complications were recorded: 9 bleeding episodes, 4 pancreatitis cases, and 4 retroperitoneal perforations. No mortality was recorded.

Conclusions: a combination of precut techniques is effective for biliary cannulation when simple cannulation and initial precut approaches fail. The safety profile differs from that in the delayed strategy, hence both should be considered alternatives, their use depending on the technical and clinical conditions prevailing for each patient, as well as endoscopist experience.
\end{abstract}

Received: $12-02-2013$

Accepted: $15-07-2013$

Correspondence: Emilio J. de la Morena Madrigal. Hospital Sanitas La Zarzuela. C/ Pléyades 25. 28023 Madrid. Spain

E-mail: emorena@sanitas.es
Key words: ERCP. Biliary cannulation. Needle-knife precut sphincterotomy. Transpancreatic precut sphincterotomy.

\section{INTRODUCTION}

Therapeutic endoscopic retrograde cholangio-pancreatography (ERCP) requires, as a mandatory technical handling, a selective cannulation of the bile duct (SBC) and/or pancreatic duct. Simple SBC techniques are successful in a relatively wide range of cases at $80-95 \%$, depending on patient anatomy and disease, and also on endoscopist experience (1). Endorsing the assumption that centres with a higher rate of SBCs using simple methods are those with greater expertise (2) and therefore a higher volume of procedures (2), these rates represent, in absolute terms, a significant number of failures that must undergo advanced SBC techniques in order to avoid alternative, more aggressive therapeutic procedures. Among reported approaches precut techniques (with a cut prior to cannulation) are most commonly used, and are currently classified into three categories ${ }^{1}$ :

- Precut sphincterotomy, defined as any technique using an incision to or from the papillary orifice, partially or fully sectioning the sphincter of Oddi. Most authors perform this using a needle-knife sphincterotome (3-15) whereas a minority employ a pull precut sphincterotome $(16,17)$.

- Precut fistulotomy, defined as any technique that creates a choledoco-duodenal fistula, thus avoiding the papillary orifice. This is performed with the needleknife sphincterotome (18-21) and, as it respects the papillary orifice, obtains similar or higher SBC rates

De-la-Morena-Madrigal EJ. Impact of combined precut techniques on selective biliary cannulation. Rev Esp Enferm Dig 2013; 105:338-344. 
with a lower incidence of pancreatitis as compared to the above technique (22-26).

- Transpancreatic precut sphincterotomy, defined as any technique cutting the pancreatic tissue between the main pancreatic duct and common bile duct. This is performed using a conventional pull sphincterotome inserted within the pancreatic duct (27-30) following its accidental or intentional cannulation. This technique is now an established alternative to both a) and b), as it has demonstrated similar or higher SBC rates with no increased incidence of post-ERCP pancreatitis $(25,26,31-35)$.

However, precut techniques allow no immediate biliary access in a variable percentage between $10 \%$ and $40 \%$ (4,6-15,18-20,27-35). In such cases, recourse may be had to an alternative precut strategy immediately following the initial failure, among other options. For instance, a needle-knife precut sphincterotomy (NPS) may be performed after a failed transpancreatic precut sphincterotomy (TPS) $(29,33,36,39)$, or a TPS procedure should a previous NPS fail to access the bile duct but not the pancreatic one (25).

The purpose of the present study was to assess the efficacy and safety of the combined, successive use of two precut strategies (NPS and TPS) when the initial approach fails to achieve immediate biliary access.

\section{PATIENTS AND METHOD}

We performed a retrospective analysis of a personal series of precut sphincterotomies (NPS and TPS), both single and combined, as SBC strategies between 2007 and 2012. All procedures were initiated and completed by the author, who at the end of 2006 had an approximate cumulative experience of 1,500 ERCPs. During the study period NPS was a consolidated technique (12) (some 150 had been performed before the study period) whereas TPS was introduced at the beginning of the study period, during which its learning curve is recorded. All patients signed a standard ERCP-related informed consent form.

Procedures were carried out in various private hospitals in Madrid using Pentax ED-3470TK ${ }^{\circledR}$ (Tokyo, Japan), Olympus TJF-145 ${ }^{\circledR}$ (Tokyo, Japan) and Fujinon ED$250 X 5^{\circledR}{ }^{\circledR}$ (Tokyo, Japan) therapeutic duodenoscopes, with Boston Scientific ${ }^{\circledR}$ (Natick MA, USA) Autotome RX-44 ${ }^{\circledR}$ cannulotomes and Jagwire/Hydra-Jagwire ${ }^{\circledR} 0.035$ " guidewires, and in a minority of cases Cook Medical ${ }^{\circledR}$ (Bloomington IN, USA) DASH-21-480 ${ }^{\circledR}$ cannulotomes and Tracer-Metro $^{\circledR} 0.021$ " guidewires. TPSs were performed with the same cannulotome used for the simple cannulation attempt, while NPSs were carried out with Cook Medical (Bloomington IN, USA) HPC-2 needle-knife sphincterotomes, and in a minority of cases with Boston Scientific (Natick MA, USA) RX Needle-Knife XL three-lumen needle-knife sphincterotomes.
NPS was performed with the classical cutting technique involving a cephalic section from the papillary orifice in an attempt to incise and expose the muscle wall of the bile duct sphincter (3). TPS is performed by cutting in the cephalicdorsal direction (towards " 11 o>clock") in an attempt to incise the bile duct wall (27). The position of the cannulotome within the pancreatic duct is confirmed by the guidewire, thus restricting pancreatography to cases where the guidewire will not advance towards the pancreatic body, thus raising doubts on its location. TPS is performed by keeping the guidewire within the pancreatic duct.

In a great majority of cases an ERBE ICC- $200^{\circledR}$ (Tübingen, Germany) diathermy generator was used. Mixed current is used for TPS, with power limited to $80 \mathrm{~W}$, coagulation set at level 3, and "endocut" mode "on" (same parameters as for conventional pull sphincterotomy). NPS has power reduced to $40 \mathrm{~W}$ with level- 2 coagulation and "endocut" mode on. Parameters are arbitrary but consistent throughout the study and based on the author>s prior experience.

Advanced cannulation is attempted whenever simple cannulation fails, there is a therapeutic indication for ERCP and no contraindications (whether technical or iatrogenic) emerge over the procedure.

Figure 1 shows the present cannulation strategy, which with minor modifications was used during the study period. SBC is initially attempted with the help of a hydrophilic guidewire with no prior cholangiography. If the pancreatic duct is cannulated 3 times within 10 minutes using the guidewire, a TPS is performed. If no SBC or SPC is obtained within 10 minutes, an NPS is performed (where extension and depth are expanded up to 3 times). If no SBC is obtained with NPS, the procedure is interrupted and will be completed later (after 3-7 days) unless the pancreatic duct is cannulated, in which case a TPS is carried out. If

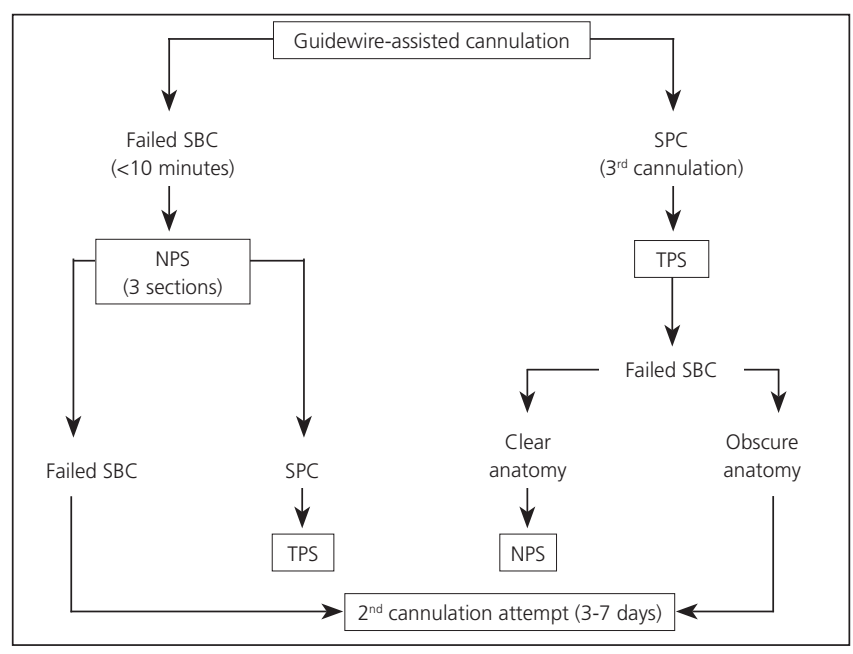

Fig. 1. Biliary cannulation strategy. NPS: needle-knife precut sphincterotomy; SBC: selective biliary cannulation; SPC: selective pancreatic duct cannulation; TPS: transpancreatic precut sphincterotomy. 
SBC fails following the initial TPS and anatomy is clear, with an apparent exposure of the bile duct intraduodenal segment, an NPS (with only one section) is performed; however, an obscure or hidden -by blood remnantsanatomy should lead to opt for a delayed second attempt. Following SBC, the precut is widened by conventional pull sphincterotomy to a size in accordance with papillary anatomy and therapeutic indication.

The efficacy analysis was performed based on endoscopic procedure reports supported by both static radiographic and video-recorded endoscopic images. The analysis covered all diagnostic or therapeutic ERCPs with whole papillae (with no previous endoscopic biliary or pancreatic sphincterotomy, surgical sphincteroplasty or ampullectomy). Explorations where the papilla cannot be accessed or identified because of strictures or anatomic distortion, duodenoscopies for extrapapillary duodenal disease, and aborted procedures from pre-cannulation complications or duodenoscope breakdown were also excluded from the analysis. Procedures completed in two times are included as one. Besides the overall analysis a stratified analysis was also carried out according to major papilla type or status, which we divide up into: a) juxta- or intra-diverticular papilla (DP), b) non-diverticular papilla (NDP), unobstructed (normal o mildly inflamed), and c) NDP, obstructed (severely inflamed, with stone impaction or with a tumour).

The safety analysis was performed based on the available printed or electronic medical records, bearing in mind that a significant percentage of patients is referred from and then returned to their site of origin with loss to followup. In some of these cases, partial information could be obtained at history taking before a second ERCP performed days, weeks or months following the first one. Pancreatitis and perforation severity was determined using prolonged hospital stays, and bleeding severity was assessed according to transfusion requirements as per previously agreed upon criteria (38). In the analysed ERCP group, no pancreatic stents were implanted with a purely preventive intent regarding post-ERCP pancreatitis.

The statistical analysis was performed using the SPSS15 statistical package with percentage comparisons for non-independent data and the $\chi^{2}$ test for independent data. The stratified analysis by papillary type/status was performed using a single-factor ANOVA and multiple comparisons post hoc.

\section{RESULTS (Fig. 2)}

During the 2007-2012 period, 760 ERCPs were performed ( $\approx 125 /$ year), 569 (75\%) of which met the analysis inclusion criteria. Seventeen were excluded for lack of papillary access, 147 for prior sphincterotomy/plasty, 7 for ampullectomy, and 5 for other reasons. Cannulation procedures in two times (computed as one) amounted to 15 .
SBC was obtained with simple methods in 444 (78\%) procedures.

SBC was attempted using NPS, TPS, or both combined in $119(21 \%)$ cases and was successful in $110(92.4 \%)$, which raised the overall cannulation rate to $97.4 \%$. In six patients where simple cannulation failed no advanced cannulation with NPS/TPS was attempted because of papillary involvement/changes by a neoplasm in three cases, a juxtapapillary diverticulum in two cases, and because the target was the pancreatic duct in the remaining case.

Of all 554 successful procedures, 14 (2.5\% of total and $12.7 \%$ of precuts) were two-times advanced cannulations. The only failed SBC during a second attempt took place 7 days after an NPS complicated with a retroperitoneal perforation.

\section{Efficacy}

Table I shows the efficacy of NPS and TPS both together and separately, as well as the impact of the alternative technique for rescue after initial failure.

Of all 119 attempted precuts, 95 (80\%) were successful with the initial approach. Rescue was attempted for 20 failures using the alternative technique, and SBC was achieved in 15 (75\%), which raised the overall success rate to $92 \%(p=0.005)$.

Of all 69 NPSs attempted, an initial SBC was obtained in $60(87 \%)$. NPS allowed pancreatic cannulation and a rescue TPS in six cases, and was successful in five (83\%), which raised the SBC rate to $94 \%(p=0.17)$. Rescue with TPS was not attempted for two patients who suffered from retroperitoneal perforations, and one with immediate postNPS bleeding.

Of all 50 TPSs attempted, an initial SBC was obtained in $35(70 \%)$. One failure was due to immediate post-TPS bleeding. In the remaining 14 cases rescue with NPS was

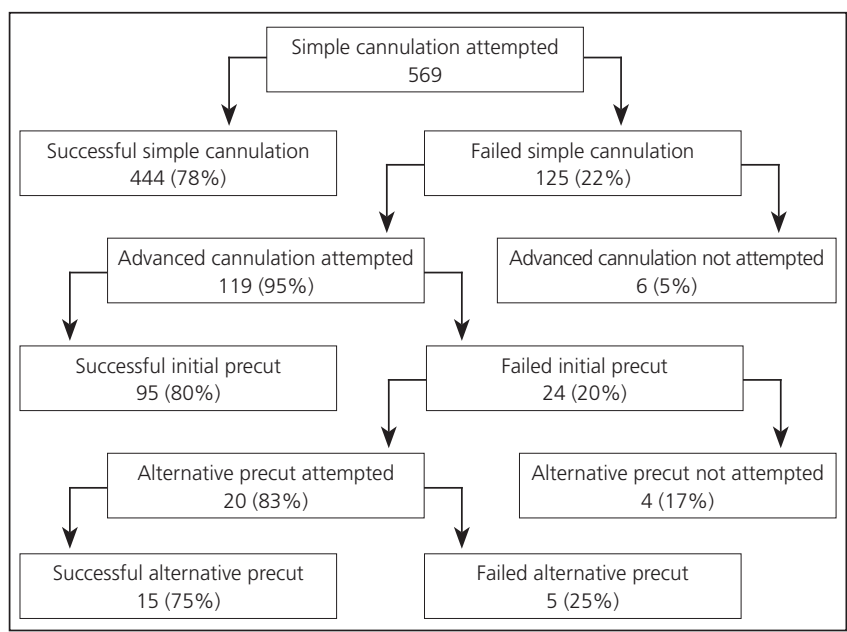

Fig. 2. Technical results from all 569 analysable ERCPs. 
attempted and was successful in $10(71 \%)$, which raised the SBC rate to $90 \%$ ( $p=0.01)$. Two failed post-NPS TPSs resulted from retroperitoneal perforations.

The stratification by papillary type/status shows a precut rate with no differences between DPs $(8 / 100 ; 8 \%)$ and unobstructed NDPs $(60 / 373 ; 16 \%)$; this rate is however significantly higher for obstructed NDPs $(51 / 96 ; 53 \%)$ as compared to the remaining two groups $(p<0.05)$.

\section{Safety}

Follow-up data are available for 96 patients (81\%) to establish the incidence and severity of immediate/early complications. In the group with 20 combined precuts follow-up data are available for $18(90 \%)$ and in the group with 15 two-times procedures for $100 \%$.

Seventeen (18\%) complications were recorded, three of them in the combined precut group. Table II shows the distribution of complications by type and severity. Overall, there were 9 bleeding episodes ( 1 severe), 4 pancreatitis ( 2 severe) and 4 retroperitoneal perforations ( 1 severe, 1 moderate, 2 unknown). Four bleeding episodes occurred in previously anticoagulated subjects. For three pancreatitis, a pancreatography was performed; for the remaining one, the pancreatic duct was cannulated with no contrast injection. All four retroperitoneal perforations were the result of NPS ( 2 initial and 2 post-TPS procedures), were detected during ERCP because of retroneumoperitoneum development, and resulted in procedure failure. NPS subjects had 2 pancreatitis, 7 bleeding events and 2 perforations. Rescue with TPS added 1 bleeding event. TPS subjects had two pancreatitis and one severe bleeding episode. Rescue with NPS added 2 perforations (Table II). In the two-times procedure group 4 (27\%) complications were recorded: one moderate perforation and one mild bleeding event after the first time, and one mild pancreatitis and one mild bleeding episode after the second time.

Table I. Efficacy of NPS and TPS, both combined and separately

\begin{tabular}{lllll}
\hline Cannulation & $n$ & Success & Rate & $(95 \% \mathrm{Cl})$ \\
\hline Single PS & 119 & 95 & 0.80 & $(0.73-0.87)$ \\
Combined PS & 20 & 15 & 0.75 & $(0.56-0.94)$ \\
Total PS & 119 & 110 & 0.92 & $(0.88-0.97)$ \\
\hline Single NPS & 69 & 60 & 0.87 & $(0.79-0.95)$ \\
Combined NPS & 6 & 5 & 0.83 & $(0.54-1.13)$ \\
Total NPS & 69 & 65 & 0.94 & $(0.89-1.00)$ \\
\hline Single TPS & 50 & 35 & 0.70 & $(0.57-0.83)$ \\
Combined TPS & 14 & 10 & 0.71 & $(0.48-0.95)$ \\
Total TPS & 50 & 45 & 0.90 & $(0.82-0.98)$ \\
\hline
\end{tabular}

NPS: neefle-knife precut sphincterotomy; PS: precut sphincterotomy; TPS: transpancreatic precut sphincterotomy.
All complications received conservative therapy with no need for surgical or radiographic procedures. Six bleeding events received endoscopic management, including the implantation of a covered, self-expandable metallic stent. No mortality was recorded.

\section{DISCUSSION}

Advanced SBC techniques should be used whenever there is a therapeutic indication and simple cannulation approaches have failed. Current data suggest their early use following a period of time below 10 minutes or fewer than 10 attempts at simple cannulation $(1,39)$, since repeated papillary trauma makes post-ERCP pancreatitis risk skyrocket (40). However, precut techniques do not systematically or in just one operation achieve SBC. For such failures, one of two strategies is necessary. First comes a delay strategy (with a second attempt at SBC several days later, when papillary inflammation from diathermy subsides) $(5,7,9,20)$ an acceptable option should the patient's clinical status allow. Albeit some authors consider twotimes procedures a technical failure $(29,41)$, the purpose of any therapeutic procedure is clinical rather than technical in nature, hence an intervention resulting in clinical success cannot be considered a failure regardless of whether one or two times were needed for completion. In our series, second times led to SBC and clinical success in 14/15 (93\%) patients. Second comes an interventionist strategy (by using a radiographic, endosonographic, or surgical approach to access the bile duct), which is more invasive and has a greater morbidity $(42,43)$.

There is, however, an option prior to this strategic decision, namely to resort to an alternative precut technique as rescue for the initial failure $(25,29,33,36,37,44)$. Although not a universal resource that may be systematically employed, it was in our experience attempted in $83 \%$ (20/24) of cases, and rescued the previously failed attempt at SBC in $75 \%(15 / 20)$ of subjects, with an added morbidity of $17 \%(3 / 18)$. These technical success and complica-

Table II. Distribution and severity of complications

\begin{tabular}{llllll}
\hline & Overall & NPS & NPS + TPS & TPS & TPS + NPS \\
\hline Total & 17 & 11 & 1 & 3 & 2 \\
\hline Pancreatitis & 4 & 2 & & 2 & \\
Bleeding & 9 & 7 & 1 & 1 & \\
Perforation & 4 & 2 & & & 2 \\
\hline Mild & 1 & 1 & & & \\
Moderate & 9 & 8 & 1 & & \\
Severe & 4 & 1 & & 2 & 1 \\
Unknown & 3 & 1 & & 1 & 1 \\
\hline
\end{tabular}

EPT: transpancreatic precut sphincterotomy; NPS: needle-knife precut sphincterotomy. 
tions rates were similar to those recorded with simple precuts $(95 / 119=80 \%$ y $14 / 78=18 \%)$. Initial precut raised the overall SBC rate from $78 \%$ to $94.7 \%$, whereas rescue with the alternative precut further raised it to $97.4 \%$. Both complication rates are exposed to potential downward biases because of the retrospective, incomplete nature of our analysis.

Taking NPS and TPS together, the SBC rate with the initial technique was $80 \%$. There is a difference in initial success between NPS $(87 \%)$ and TPS $(70 \%)(p=0.023)$ that might partly be accounted for by the TPS-related learning curve. This hypothesis is supported by the increased rate of SBC with TPS recorded since our preliminary communication (EJ de la Morena. Técnicas combinadas de precorte biliar [poster]. XXXII Jornada Nacional de la SEED. León 2010), which rose from $62 \%$ (16/26) in the first 42 months to $79 \%(19 / 24)$ during the last 30 . Alternative precut raised SBC rate from $80 \%$ to $92 \%$, which shows the usefulness of this strategy as employed using a selective approach.

Taken separately, the increase in SBC with the NPS + TPS combination is smaller when compared to TPS + NPS (7\% vs 20\%). This is observed despite the fact that the NPS + TPS combination is more effective than TPS + NPS ( $83 \%$ vs $71 \%$ ), and directly results from the aforementioned higher SBC rate with in initial NPS as compared to initial TPS ( $87 \%$ vs $70 \%)$. The NPS + TPS combination is also safer (rescue with TPS resulted in only one additional bleeding event) than TPS + NPS (rescue with NPS resulted in 2 additional perforations). This combination of efficacy and safety leads to recommend the NPS + TPS strategy in the few cases (9\% [6/69] of attempted NPSs in our series) where pancreatic cannulation is achieved following initial NPS.

To our knowledge, there is only one previous report on the NPS + TPS (25) combination, which described only 3 patients (10\% of attempted NPSs) where SBC could be achieved, in 2 of them, during a second procedure. The authors do not report whether complications were recorded for these 3 patients.
Albeit the TPS + NPS combination is highly effective, the increase in SBC rate will likely decrease with the learning curve for TPS as initial SBC rate grow higher. Nevertheless, even though one study reports $100 \%$ of initial cannulations following TPS (33), most find rates between $56 \%$ and $87 \%$ (28-30,33-37), a range within which our $70 \%$ falls; therefore, we may have likely completed our learning curve and this percentage will not significantly grow with further cumulative experience. Of note, the most extensive TPS + NPS series ever reported (37) records the lowest SBC rate for initial TPS (56\%), which may be interpreted as a deliberate strategy for early resort to rescue NPS.

Table III shows the reported experience with combined precuts, including the present paper, where the TPS + NPS combination represents a majority. Three of them $(29,33,37)$ include only 19 cases with no specific comments. The two more extensive reports $(36,44)$ describe the technique and its results in a total of 156 patients. Both report a cannulation success rate (in one or two procedures) of $100 \%$ with a low though conflicting morbidity. While Halttunen et al. (36) record $8 \%$ of pancreatitis, Espinel et al (44) only find $2 \%$ of bleeding events. Our short series only achieves a success rate of $70 \%$ with a morbidity of $14 \%$ as retroperitoneal perforations. Both immediate bleeding and perforation may be directly attributed to rescue NPS. In contrast, the multifactorial nature of pancreatitis does not allow its attribution to a specific handling but rather to the procedure as a whole (simple biliary cannulation attempt, pancreatic cannulation with or without pancreatography, initial TPS and rescue NPS). The study by Espinel et al. (44) has been published in abstract form, hence accurate technical comparisons are not feasible. However, by examining their previous report on TPS (30) some differences may be worked out. Halttunen et al. perform the initial TPS procedure with pure-cut current, and then extend it to a length "similar to biliary sphincterotomy" (36). Espinel et al. use mixed current to perform a limited incision with the distal $5 \mathrm{~mm}$ of the sphincterotome in order to

Table III. Reported experience with combined precuts

\begin{tabular}{llllll}
\hline Author & Technique & $n(\%$ initial PS) & Successful SBC (1/2T) & Failure & Complication \\
\hline Horiuchi (25) & NPS + TPS & $3(10 \%)$ & $1 / 2$ & 0 & N/A \\
De la Morena* & NPS + TPS & $6(9 \%)$ & $4 / 1$ & 1 & 1 PSB \\
Kahaleh (29) & TPS + NPS & $6(5 \%)$ & 6 & 0 & N/A \\
Karpetanos (33) & TPS + NPS & $6(11 \%)$ & 4 & 2 & 1 PSP \\
Halttunen (36) & TPS + NPS & $108(42 \%)$ & 108 & 0 & $8.2 \%$ PSP \\
Chan (37) & TPS + NPS & $7(13 \%)$ & 7 & 0 & 0 \\
Espinel (44) & TPS + NPS & $48(28 \%)$ & $40 / 8$ & 0 & 1 PSB \\
De la Morena* & TPS + NPS & $14(28 \%)$ & $8 / 2$ & 4 & 2 RPP \\
\hline
\end{tabular}

*Present study.

NPS: needle-knife precut sphincterotomy; PSB: post-sphincterotomy bleeding; PSP: post-sphincterotomy pancreatitis; RPP: retroperitoneal perforation; SBC: selective biliary cannulation; TPS: transpancreatic precut sphincterotomy. 
prevent "eventually damaging the pancreatic sphincter" (30). Pancreatography and prophylactic pancreatic stent implantation rates are not available. It seems reasonable that the differing morbidity profile be attributed to these or other technical variations.

In our case, the significant risk of retroperitoneal perforation with rescue NPS might be attributed to the use of mixed current with a high coagulation component during initial TPS. Our historic morbidity profile, where bleeding predominates over pancreatitis, advises that TPS be performed with coagulation set to effect 3 , which may blur the view of exposed tissues and render difficult the identification of the bile duct intraduodenal segment, on which the rescue NPS is to be carried out. A review of the recordings from the two TPS + NPS procedures complicated with a retroperitoneal perforation confirms this and renders caution mandatory, with rescue NPS being only performed in cases with a clear anatomy. Otherwise a delayed strategy should be used, which -although with a somewhat higher rate of complications - seems to prevent serious complications apt to result in a failed procedure.

To conclude, a combination of precut techniques is effective to achieve SBC when simple cannulation and initial precut fail. Its safety profile (fewer but more severe complications) differs from that of the delayed strategy, hence both must be considered alternative procedures and should be used according to the technical and clinical factors of each patient and the experience and preferences of the endoscopist.

\section{ACKNOWLEDGEMENTS}

I am grateful to Dra. Isabel Rodríguez-García for her review of the statistical analysis, and to Drs. E. PérezArellano, Y. González-Lama and A. Albillos, as well as the nursing staff, for their help in performing the procedures.

\section{REFERENCES}

1. DaVee T, García JA, Baron TH. Precut sphinceterotomy for selective biliary duct cannulation during endoscopic retrograde cholangiopancreatogaphy. Ann Gastroenterol 2012;25:291-302.

2. Varadarajulu S, Kilgore ML, Wilcox CM, Eloubeidi MA. Relationship among hospital ERCP volume, length of stay and technical outcomes. Gastrointest Endosc 2006;64:338-47.

3. Huibregtse K, Katon RM, Tytgat GNJ. Precut papillotomy via fine needle-knife papillotome: a safe and effective technique. Gastrointest Endosc 1986;32:403-5.

4. Conio M, Saccomanno S, Aste H, Pugliese V. Precut papilllotomy: primum non nocere. Gastrointest Endosc 1990;36:544.

5. Dowsett JF, Polydorou AA, Vaira D, D'Anna LM, Ashraf M, Croker $\mathrm{J}$, et al. Needle-knife papillotomy: how safe and how effective? Gut 1990;31:905-8.

6. Tweedle DEF, Martin DF. Needle-knife papillotomy for endoscopic sphincterotomy and cholangiography. Gastrointest Endosc 1991;37:518-21.

7. Shakoor T, Geenen JE. Pre-cut papillotomy. Gastrointest Endosc 1992;38:623-7.
8. Foutch PG. A prospective assessment of results for needle-knife papillotomy and standard endoscopic sphincterotomy. Gastrointest Endosc $1995 ; 41: 25-32$

9. Bruins Slot W, Schoeman MN, Disario JA, Wolters F, Tytgat GNJ, Huibregtse K. Needle-knife sphincterotomy as a precut procedure: a retrospective evaluation of efficacy and complications. Endoscopy 1996;28:334-9

10. Rabenstein T, Ruppert T, Schneider T, Hahn EG, Ell C. Benefits and risks of needle-knife papillotomy. Gastrointest Endosc 1997;46:207-11.

11. Rollhauser C, Johnson M, Al-Kawas FH. Needle-knife papillotomy: a helpful and safe adjunct to endoscopic retrograde cholangiopancreatograpy in a selected population. Endoscopy 1998;30:691-6.

12. De la Morena EJ, Domínguez M, Lumbreras M, Opio V, Moyano E, García Álvarez J. Aprendizaje no tutelado de la esfinterotomía de aguja. Gastroenterol Hepatol 2000;23:109-15.

13. Bolzan HE, Spatola J, González J, Luna R, García G. Precorte de papila de Vater. Evaluación prospectiva de frecuencia de uso, eficacia, complicaciones y mortalidad. Estudio cooperativo del Noroeste de la provincia de Buenos Aires. Acta Gastroenterol Latinoam 2001;31:323-7.

14. Katsinelos P, Mimidis K, Paroutoglou G, Christodoulou K, Pilpilidis I, Katsiba D, et al. Needle-knife papillotomy: a safe and effective technique in experienced hands. Hepatogastroenterology 2004;51:349-52.

15. Espinel Díez J, Vivas Alegre S, Muñoz Núñez F, Domínguez Carbajo A, Villanueva Pavón R, Jorquera Plaza F, et al. Esfinterotomía de aguja como técnica de acceso a la vía biliar: estudio prospectivo. Gastroenterol Hepatol 2005;28:369-74.

16. Siegel JH. Precut papillotomy: a method to improve success of ERCP and papillotomy. Endoscopy 1980;12:130-3.

17. Binmoeller KF, Seifert H, Gerke H, Seitz U, Portis M, Soehendra $\mathrm{N}$. Papillary roof incision using the Erlangen-type pre-cut papillotome to achieve selective bile duct cannulation. Gastrointest Endosc 1996;44:689-95.

18. Siegel JH, Ben-Zvi JS, Pullano W. The needle-knife: a valuable tool in diagnostic and therapeutic ERCP. Gastrointest Endosc 1989;35:499503.

19. Leung JWC, Banez VP, Chung SCS. Precut (needle-knife) papillotomy for impacted common bile duct stone at the ampulla. Am J Gastroenterol 1990;85:991-3.

20. Kasmin FE, Cohen D, Batra S, Cohen SA, Siegel JH. Needle-knife sphincterotomy in a tertiary referral center: efficacy and complications. Gastrointest Endosc 1996;44:48-53.

21. Gholson CF, Favrot D. Needle knife papillotomy in a university referral practice. Safety and efficacy of a modified technique. J Clin Gastroenterol 1996;23:177-80.

22. Mavrogiannis C, Liatsos C, Romanos A, Petoumenos C, Nakos A, Karvountzis G. Needle-knife fistulotomy versus needle-knife precut papillotomy for the treatment of common bile duct stones. Gastrointest Endosc 1999;50:334-9.

23. Abu-Hamda EM, Baron TH, Simmons DT, Petersen BT. A retrospective comparison of outcomes using three different precut needle knife techniques for biliary cannulation. J Clin Gastroenterol 2005;39:717-21.

24. Kaffes AJ, Sriram PV, Rao GV, Santosh D, Reddy DN. Early institution of pre-cutting for difficult biliary cannulation: a prospective study comparing conventional vs. a modified technique. Gastrointest Endosc 2005;62:669-74.

25. Horiuchi A, Nakayama Y, Kajiyama M, Tanaka N. Effect of precut sphincterotomy on biliary cannulation based on the characteristics of the major duodenal papilla. Clin Gastroenterol Hepatol 2007;5:1113-8.

26. Katsinelos P, Gkagkalis S, Chatzimavroudis G, Beltsis A, Terzoudis $\mathrm{S}$, Zavos C, et al. Comparison of three types of precut technique to achieve common bile duct cannulation: a retrospective analysis of 274 cases. Dig Dis Sci 2012;57:3286-92.

27. Goff JS. Common bile duct pre-cut sphincterotomy: transpancreatic sphincter approach. Gastrointest Endosc 1995;41:502-5.

28. Akashi R, Kiyozumi T, Jinnouchi K, Yoshida M, Adachi Y, Sagara K. Pancreatic sphincter precutting to gain selective access to the common bile duct: a series of 172 patients. Endoscopy 2004;36:405-10.

29. Kahaleh M, Tokar J, Mullick T, Bickston SJ, Yeaton P. Prospective evaluation of pancreatic sphincterotomy as a precut technique for biliary cannulation. Clin Gastroenterol Hepatol 2004;2:971-7.

30. Espinel-Díez J. Acceso a la vía biliar mediante esfinterotomía transpancreática. Gastroenterol Hepatol 2006;29:281-5. 
31. Goff JS. Long-term experience with the transpancreatic sphincter pre-cut approach to biliary sphincterotomy. Gastrointest Endosc 1999;50:642-5.

32. Catalano MF, Linder JD, Geenen JE. Endoscopic transpancreatic papillary septotomy for inaccessible obstructed bile ducts: comparison with standard pre-cut papillotomy. Gastrointest Endosc 2004;60:557-61.

33. Karpetanos D, Kokozidis G, Christodoulou D, Mistakidis K, Dimakopoulos K, Katodritou E, et al. Case series of transpancreatic septotomy as precutting technique for difficult bile duct cannulation. Endoscopy 2007;39:802-6

34. Wang P, Zhang W, Liu F, Li ZS, Ren X, Fan ZN, et al. Success and complication rates of two precut techniques, transpancreatic sphincterotomy and needle-knife sphincterotomy for bile duct cannulation. J Gastrointest Surg 2010;14:697-704.

35. Weber A, Roesch T, Pointner S, Born P, Neu B, Meining A, et al. Transpancreatic precut sphincterotomy for cannulation of inaccessible common bile duct: a safe and successful technique. Pancreas 2008;36:187-91.

36. Halttunen J, Keränen I, Udd M, Kylänpää L. Pancreatic sphincterotomy versus needle knife precut in difficult biliary cannulation. Surg Endosc 2009;23:745-9.

37. Chan CH, Brennan FN, Zimmerman MJ, Ormonde DG, Raftopoulos SC, Yusoff IF. Wire assisted transpancreatic septotomy, needle knife precut or both for difficult biliary access. J Gastroenterol Hepatol 2012;27:1293-7.
38. Cotton PB, Lehman G, Vennes J, Geenen JE, Russell RC, Meyers WC, et al. Endoscopic sphincterotomy complications and their management: an attempt at consensus. Gastrointest Endosc 1991;37: 383-93.

39. Cennamo V, Fuccio L, Zagari RM, Eusebi LH, Ceroni L, Laterza $\mathrm{L}$, et al. Can early precut implementation reduce endoscopic retrograde cholangiopancreatogrphy-related complication risk? Metaanalysis of randomized controlled trials. Endoscopy 2010;42: 381-8.

40. Bailey AA, Bourke MJ, Kaffes AJ, Byth K, Lee EY, Williams SJ. Needle-knife sphincterotomy: factors predicting its use and the relationship with post-ERCP pancreatitis. Gastrointest Endosc 2010;71:266-71.

41. Freeman ML, Guda NM. ERCP cannulation: a review of reported techniques. Gastrointest Endosc 2005;61:112-25.

42. Weber A, Gaa J, Rosca B, Born P, Neu B, Schmid RM, et al. Complications of percutaneous transhepatic biliary drainage in patients with dilated and nondilated intrahepatic bile ducts. Eur J Radiol 2009;72:412-7.

43. Pérez-Miranda M, Barclay RL, Kahaleh M. Endoscopic ultrasonography-guided endoscopic retrograde cholangiopancreatography. Endosonographic cholangiopancreatography. Gastrointest Endoscopy Clin N Am 2012;22:491-509.

44. Espinel J, Pinedo E, Vaquero L, Álvarez B. Esfinterotomía combinada en el acceso a la vía biliar [Abstract]. Endoscopy 2012;44:1074. 